\title{
ASSESSMENT OF LANDSCAPE QUALITY BASED ON THE PERCEPTION OF PEOPLE: STUDY OF TWO PARKS IN NEWCASTLE UPON TYNE
}

\author{
SEPIDEH SHAHAMATI* \\ Department of Geography, Planning and Environment, Concordia University, Montreal, \\ 1455 De Maisonneuve Blvd. W. Montreal, QC H3G 1M8, Canada \\ *Corresponding author: sepideh.shahamati@gmail.com
}

\begin{abstract}
People experience different types of landscapes every day. The quality of these landscapes has a major effect on their psychological well-being and general satisfaction of a place. Determining the quality of landscapes is an important issue for policy makers and planners, especially when making decisions about the conservation or transformation of urban landscapes. Defining quality based on people's perception has received significant attention from planners and decision makers as it can lead to greater public involvement and improve the reliability of the decisions. This research aimed to determine the criteria important for landscape quality assessment by using walk-and-talk interviews in two green landscapes in Newcastle upon Tyne (UK). The attributes affecting people's choices include naturalness, locomotion, smoothness, surprise, variety, sense of place, tranquillity, rarity, legibility, safety, complexity, mystery, openness, accessibility, maintenance and management. Not all of these attributes have the same weight, as some are more influential in determining people's preferences, however, categorizing them into primary and secondary attributes, provided a means of evaluating landscape that is less costly and time-consuming
\end{abstract}

Keywords: landscape evaluation; landscape perception; landscape quality attributes; people's preferences; urban parks

\section{Introduction}

The word landscape comes from the German word "Landschaft" meaning a bounded area and the Dutch word "landchap" meaning a visual or artistic perceived area (Selman 2012). Nan Fairbrother (1970) states that landscape is a separate concept from nature and describes the interaction between society and its habitat, and Cosgrove and Daniels (1988) define it as a cultural image of the surrounding area. In most contemporary definitions and more specifically the European Landscape Convention, landscape is seen and understood in the eyes, mind, and heart of beholders with an emphasis on cultural values (Fairclough 2002). Thus, currently landscape is regarded as "an area, as perceived by people, whose character is the result of the action and interaction of natural and/or human factors" (Ahern et al. 2009).

Landscapes are experienced by a range of people on a daily basis and affect their psychological well-being and general satisfaction of places (Ruelle et al. 2013). The quality of landscapes has a direct effect on the quality of life. It affects people's satisfaction with cities, their perspective of cities and personal situations. It can be regarded as one of the factors determining the quality of life for communities (Gavrilidis et al. 2016). Visual attributes of surrounding landscapes can affect a citizen's satisfaction and be a factor in determining whether they leave a city (Barreira et al. 2019). People's satisfaction with landscapes can provide an opportunity to make the local community liveable in, increase the sense of place and reduce un-civic behaviour (Ruelle et al. 2013). In contrast, several studies show that renewal programs and urban interventions that do not integrate people's perception and satisfaction are likely to result in boycotting the interventions or even vandalism (Sharp et al. 2005;
Orueta 2007; Ruelle et al. 2013). Therefore, considering people's preferences for landscapes is highly important for planners and policymakers.

This study seeks to determine people's perception of quality. What people perceive and the rationale of their preferences are important for determining how landscapes are evaluated. In order to address the aim of this research, the main characteristics influencing their judgments need to be identified. This will be done by comparing people's view of two urban landscapes (parks) one of which is reclaimed industrial wasteland. The attributes of these two parks will be compared in order to identify the attribute(s) important in determining their quality as landscapes and the rationale behind people's perception of the quality of landscapes.

To achieve this aim, three questions were addressed:

1. What are the important attributes?

2. How do these attributes determine quality?

3. Are all the attributes equally important?

\section{Methodology}

A case study approach was used to provide detailed information on landscape quality in a real-life context (Crowe et al. 2011) and provide conceptual validity in terms of the identification and measurement of indicators of quality (Starman 2013). The data was obtained from walk and talk interviews recorded in two green spaces (parks) in Newcastle upon Tyne. Riverside Park, which is recently reclaimed industrial wasteland where the city landscaped the naturally grown vegetation. Exhibition Park is a well-designed urban park. These two parks differ in that one mainly consists of naturally developing vegetation and the other is well-designed with well-maintained 
areas of grass. Comparing the reaction of people to these two parks will clarify the reaction of people to semi-natural landscapes and endemic flora and fauna. In addition, these two parks have different social characteristics. The nature of the questions asked in the interviews was determined by the attributes cited in the literature.

This study used semi-structured interviews with specific groups of people to determine why they have a particular attitude towards a place or phenomenon. Although most landscape preference studies use surveys and questionnaires along with photographs or computer visualizations (Ruelle et al. 2013), the responses are often limited by the quality of photographs or range of questions in the questionnaires.

Interviews provide scope for determining the rationale of each response. Interviews can be conducted with either groups or single individuals (Dicicco and Crabtree 2006). In one-to-one interviews, the interviewees are not challenged and may not provide considered answers, whereas group interviews often result in a discussion that results in a more considered response (Bryman 2001). It is suggested that the number of participants in such groups should be between 6 to 10 people (Bryman 2001) as when the number of interviewees exceeds 6 or 7 , the answers tend to be the same (Coeterier 1996). If the interviewees are familiar with one another, the discussion is likely to be more natural (Bryman 2001). Based on this information, seven female master students of Newcastle University from five different countries participated in this study. The interviewees were all in their 20s but with different educational backgrounds in that they were either studying Landscape Architecture, Urban Planning, Communication, Linguistics or Software Engineering. They were invited through social media.

One of the important characteristics of the interviews is that they were carried out while walking in a particular landscape. Mobile interviews result in the discovery of new spaces and subjects for discussion (Macpherson 2016). In addition, this is an ideal technique for obtaining more detailed data due to the connection between the interviewees and surrounding environment (Evans and Jones 2011). Mobility while talking is more likely to reveal issues (Jones et al. 2008) and facilitate discussion (Macpherson 2016). This approach is thought to more likely reveal, how different people value landscapes (Macpherson 2016), which is important for understanding landscape quality. Thus, the data used in this study were obtained from interviews, which was compared with that in the literature. The overall structure of this research is presented below (Fig. 1).

\section{Literature Review}

\section{Paradigms of landscape quality assessment}

Landscape quality evaluations can be categorized into monetary and non-monetary (Tempesta 2014). There are two categories of non-monetary: objectivist (expert-de-

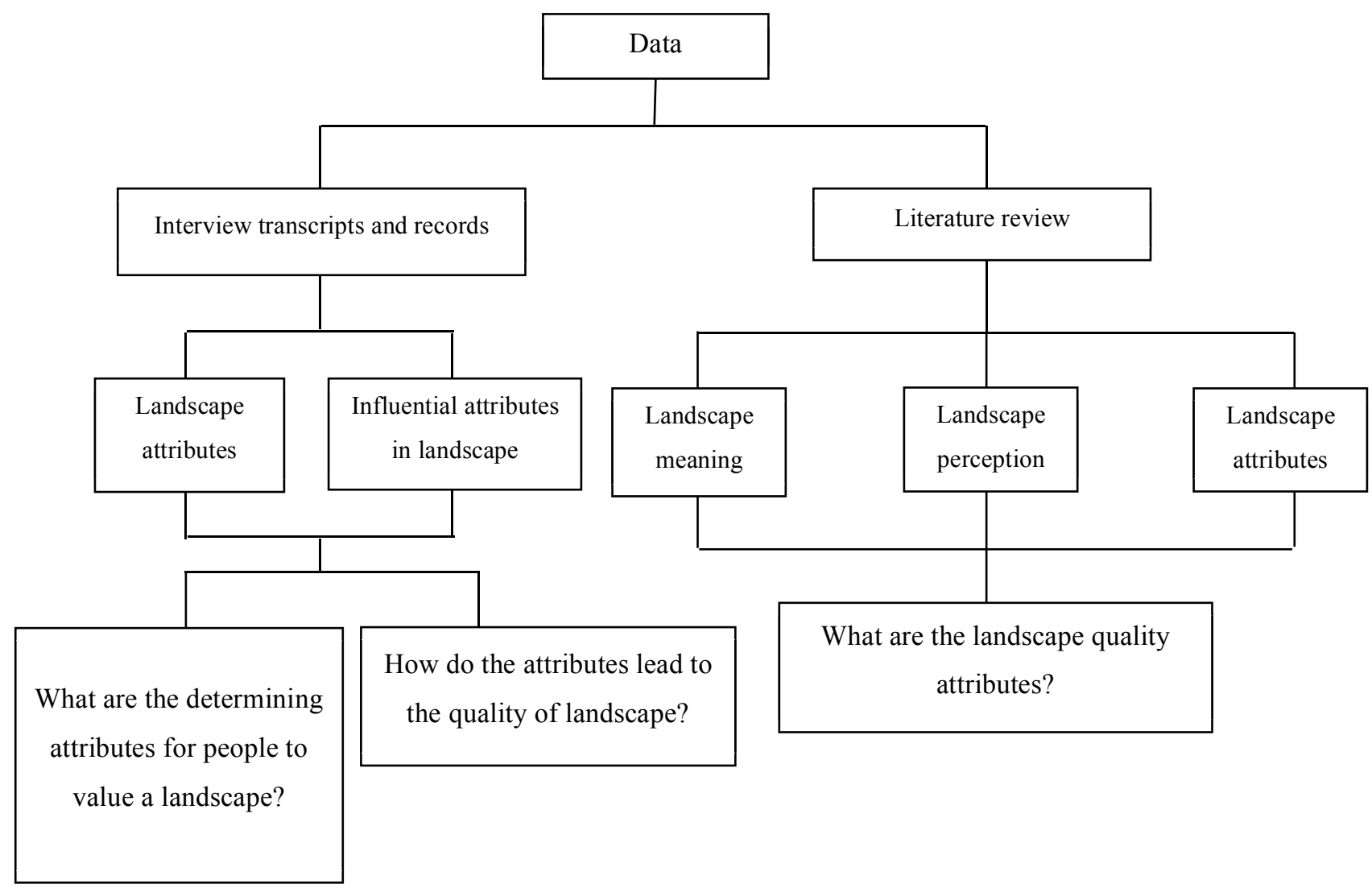

Fig. 1 Structure of the study. 
sign approach) and subjectivist (community perception-based approach), which differ in terms of their specific views on landscapes (Pouya and Behbahani 2017). In the former, the visual quality is considered to be inherent to landscapes and in the latter the quality is in the eye of the beholder (Lothian 1999; De Val et al. 2006). The monetary approach has various categories: supply based, demand-based, revealed preferences and stated preferences, which can be useful for analysing the cost-benefit of large infrastructure projects, the effectiveness of subsidies given to farmers for improving the landscape, or payments for damage caused by landscape transformation (Tempesta 2014). The monetary approach is not used in this study, which is based entirely subjective.

An expert-approach evaluates and inspects landscapes based on the view of a trained expert (Daniel 2001). In this approach, the biophysical features of landscapes (mountains, lakes, etc.) are transformed into parameters (De Val et al. 2006) such as form, texture, colour and line and are ranked in terms of quality from low to high. This approach is objective and based on the assumption that landscape quality is determined by its physical features. The human aspect is acknowledged in terms of viewpoints, location, number of viewers and sensitivity (Daniel 2001). In contrast, the perception-based approach emphasizes the human view of landscapes (Wu et al. 2006) and regards landscape quality as being in the eye of the beholder (Pouya and Behbahani 2017). Various landscape studies using this approach introduce derived perceptual factors of landscape (Daniel 2001) and the emotional responses of people to different landscapes. More specifically it reveals the role of landscape in mediating emotional responses (Zube et al. 1974; Parsons et al. 1998) and/or it effect on health (Seymour 2016; Frumkin et al. 2017). That is this approach is based on the sensory, emotional and cognitive factors of the relationships of people with landscapes (Daniel 2001).

During the last decade, there were several subjective studies on landscape quality. In such a study of the visual quality of urban landscapes Keshtkaran et al (2017) use elements of visual design to assess their physical quality using pictures (Bell 2004). Pouya and Behbahani (2017), in a similar study, use pictures to assess the quality of the landscapes in two memorial gardens. In addition, to the physical elements of landscape other concepts such as stewardship, coherence, disturbance, historicity, visual scale, image ability, complexity and naturalness are identified in the review of the key concepts of landscape quality by Tveit and Fry (2006). The above highlight specific indicators of landscape quality and below the literature on the assessment of landscape quality will be reviewed.

\section{Attributes used to assess landscape quality}

Most of the preference studies on landscape quality were done after 1960 by Appleton (1975), Anderson (1978), Kaplan (1979), Zube (1987), Nassauer (1995), Coeterier (1996), Swanwick (2002) and Burton and Rym-
sa-Fitschen (2008) were reviewed and analysed in this study in order to determine the attributes for assessing landscape quality.

Kaplan (1979) assumes preference is a complex process, which includes perception and reaction in terms of usefulness and supportiveness. He believes that it is important to understand people's preferences and show they are not idiosyncratic. There might be patterns in the preferences (Kaplan 1979) and differences between groups' people in their preferences for a landscape (Rogge et al. 2007). Kaplan (1979) propose two underlying purposes: 'making sense' and 'involvement', for identifying the preference of people for landscapes. Making sense is about understanding what is currently stimulated by it, with those landscapes inducing these responses being the preferred (Coeterier 1996).

Coeterier (1996) suggests complexity is an important attribute determining preference for a landscape. "Complexity" in terms of "diversity" or "richness" is seen as an important characteristic of landscapes. Kaplan et al. (1998) relate complexity to coherence and argue that too much complexity has a negative effect on coherence as it makes a landscape difficult to comprehend. Coherence is achieved by having identifiable components, such as "legibility", which is the ability to be able to interpret and understand the structure and perceive a landscape (Zube 1987). "Openness", which is 'the amount of space perceivable to a viewer', "smoothness" - the 'uniformity of ground texture', and "locomotion" - the 'ease of traversing without undue effort' are important features of a landscape that can affect people's preference (Kaplan et al. 1989). They investigated these attributes along with "spaciousness", which is the amount of room for wandering. Previous studies on spaciousness (Gallagher 1977; Anderson 1978) see it as a negative attribute. Some authors discuss different components of spaciousness, particularly openness and state that whether it is a positive or negative feature depends on the location (Rogge et al. 2007) and in some cases can even lead to the feeling of calmness (report of the Research Box (2009) for Natural England).

"Mystery" is another aspect, which may increase willingness to explore a landscape (Kaplan 1979), but might be mistaken for "novelty" or "surprise". Novelty implies exploring something new and surprise finding something unexpected (Zube 1987). Mystery can be provided by features like curved paths. Although some people think that dense vegetation increases the mystery of a place Kaplan et al. (1998) state that landscapes in which the view is limited lack mystery.

"Management" is considered to be important in terms of increasing the quality of a landscape (Rogge et al. 2007), especially if it includes maintenance, rules for safety issues and provision of facilities. The criteria of this attribute mean that its effects may depend on the landscape. Too much maintenance is viewed negatively, as it can result in an artificial and restrictive landscape, and too little, in an 
appearance of negligence or vandalism (Coeterier 1996). "Variety" is also of interest, as places with high variety are valued (Rogge et al. 2007) for providing people with chances for learning and discovery, however, simplicity is also appreciated as it can result in unity, especially in small-scale landscapes. In the report of Research Box (2009), simplicity is considered as a feature that can provide amenity benefits such paths for cycling or a playing field and a sense of tranquillity and calmness.

"Unity" is one of the attributes proposed by Coeterier (1996) and is defined as the situation when all the parts fit together and function as a whole giving the landscape an air of completeness.

"Naturalness", which is the impression that the environment is natural in terms of the flora and fauna (Coeterier 1996), is always mistaken for ecological quality (Nassauer 1995). Appreciating naturalness and the extent to which this attribute is considered positive, depends on our view of culture (Appleton 1975). Even the most fundamental elements of nature and vegetation are perceived through cultural lenses. Generally, it is believed that people prefer natural landscapes, however, what they are more likely to prefer is not viewed in terms of ecological quality because it tends to be messy (Nassauer 1995). They appreciate nature, but only when it is present in landscapes that are designed (Appleton 1975). People prefer natural landscapes, as they are green and predominantly rural, but clearly man-made features make them more desirable. The Research Box (2009) study revealed that people prefer rugged and isolated landscapes when seeking adventure and discovery, but otherwise designed green spaces and areas with few natural elements and more man-made features. Kaplan et al. (1998) considers natural landscapes to be unsuitable for most people, as they lack a clear focus and might provoke concerns of becoming lost.

Sensory impressions of people of colours, smell, taste, sound, humidity, temperature, light and shadow affect their perception and preference, and can give a "sense of identity" to a place (Coeterier 1996). "Safety" is another important attribute that can greatly affect people's pref-

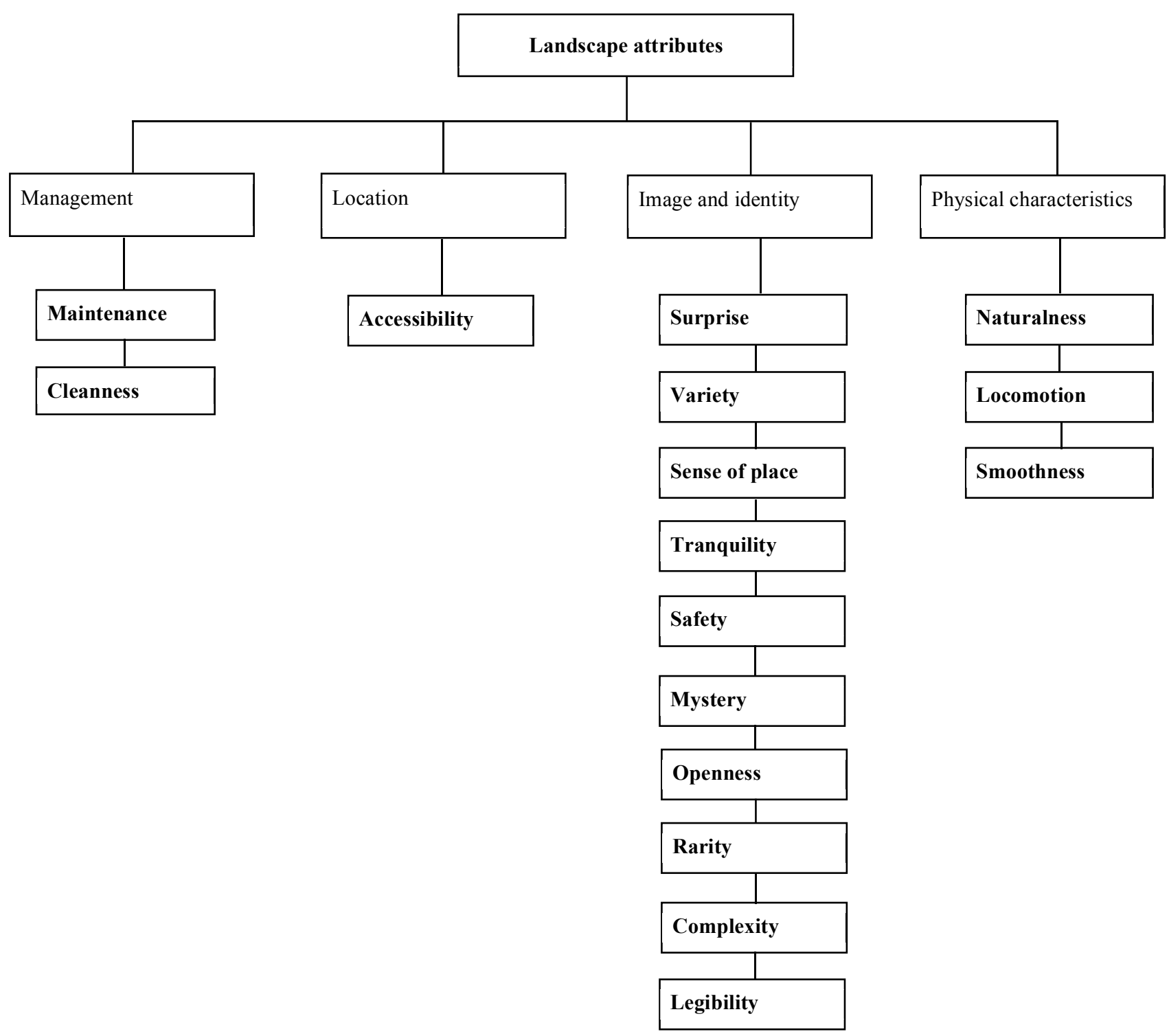

Fig. 2 Attributes of Landscape Quality. 


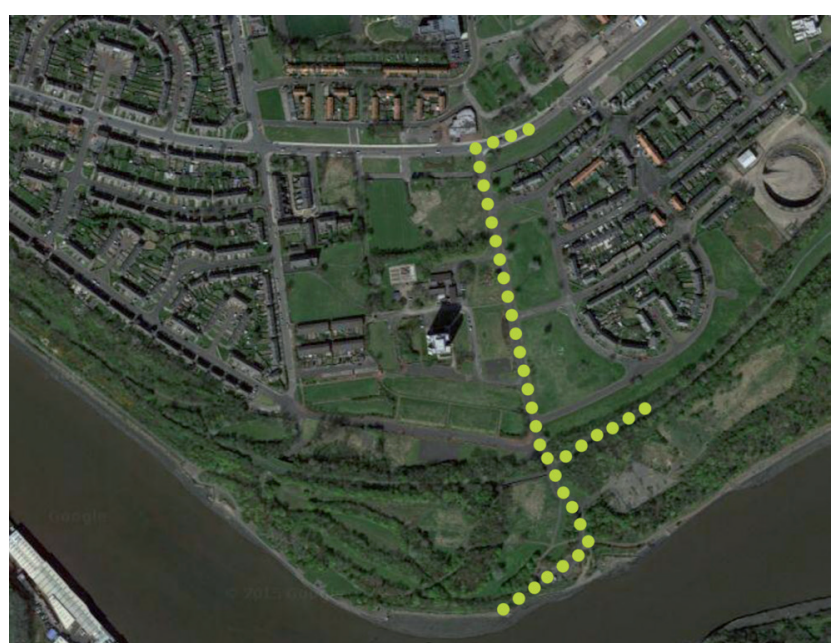

Fig. 3 Route in Riverside Park along which people were interviewed (Source: Google maps).

erences. It is viewed as a sense of fear by Kaplan et al. (1998) that many people experience when entering an unfamiliar landscape, which engenders a sense of fear. In this context, visual access is important, as landscapes with dense vegetation that restricts their view is likely to increase their sense of fear. The sign of human involvement in a landscape, such as fences and walls, can reduce the fear factor (Kaplan et al. 1998).

"Location" of the site and "accessibility" are additional features that can affect people's preferences (Burton and Rymsa-Fitschen 2008). Swanwick (2002) introduces features such as "rarity", if there is a rare feature in a land-

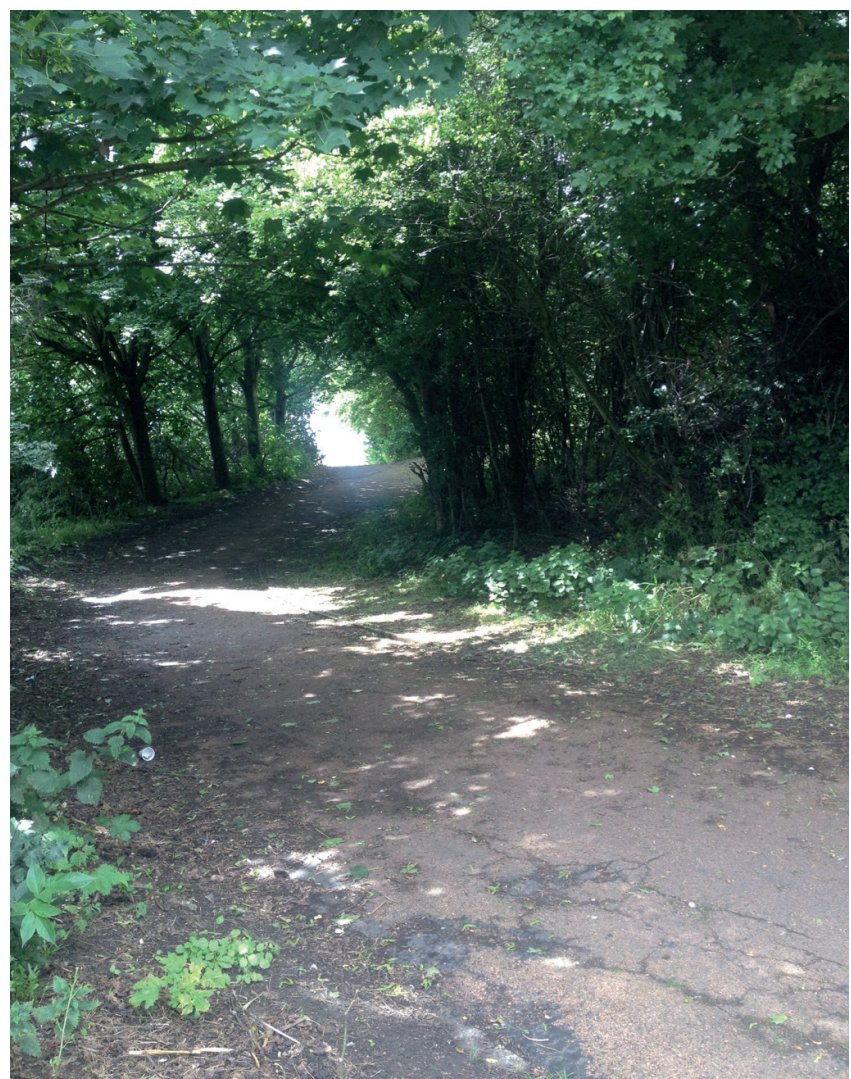

scape and "tranquillity", if the noise level and light from adjacent built up areas is low.

Based on the above people's preferences for a landscape are affected by the following attributes: management, location, image and identity, physical characteristics, each of which are determined by one or more features (Fig. 2).

\section{Case Study and Findings}

\section{Riverside Walker Park (St. Anthonys), Newcastle upon Tyne}

Riverside Park is located in the St Anthony's area in south-eastern Newcastle upon Tyne. It was occupied by heavy industry in the past and after 1980 the land was reclaimed and now consists of large areas of grassland and woodland with a spectacular view of the River Tyne (Emms 2006). Like many other wastelands, this area became available as a result of industrial decline (Mah 2010), but subsequently became a site of high ecological value, with a great range of habitats and dense woodland and scrub inhabited by many species of animals, such as birds, foxes and rabbits (Emms 2006). Nevertheless, the City Council was worried by the level vandalism and decided to develop the area with the view of making it more attractive for the public. The interview route of Riverside Park is shown in the following map (Fig. 3).

It is a large area that has been recolonized by nature where one can walk, cycle or go fishing, as there are several cycle ways and footpaths through the site and along

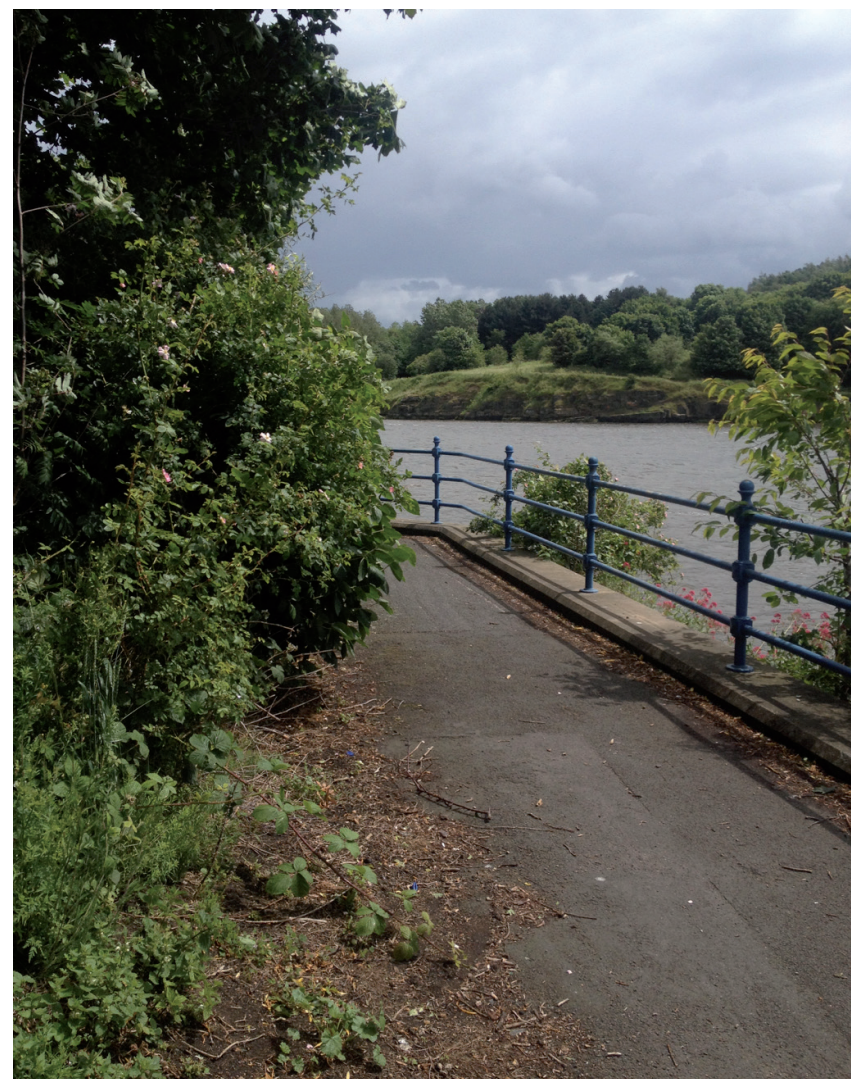

Fig. 4 Vegetation in Riverside Park (Source: author). 


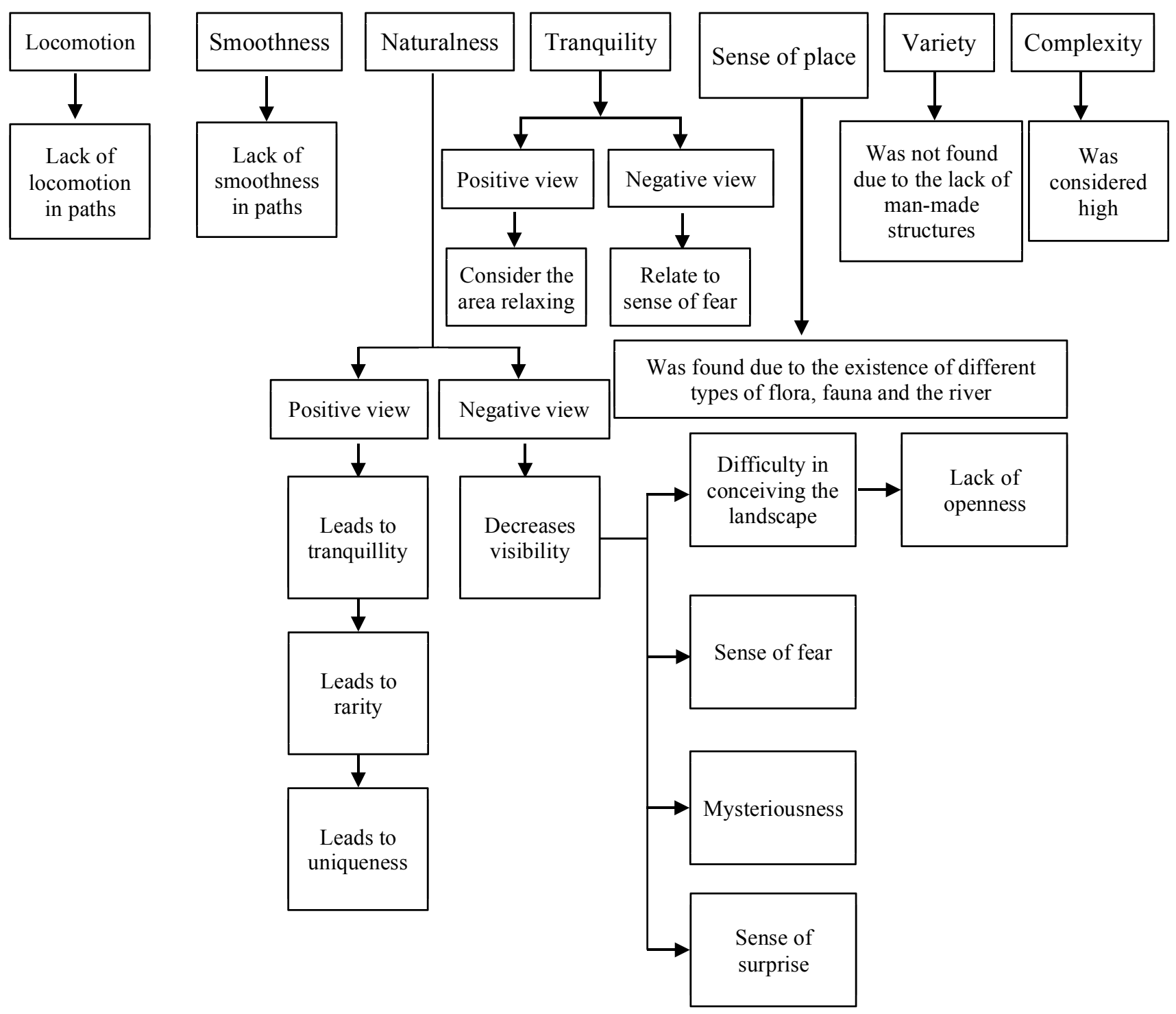

Fig. 5 Summary of the results for Riverside Park.

the river. It is located near several bus stations with direct and quick ( $<20$ mins) access to the city centre. City council improved the foot and cycle paths, provided linkages for green corridors, cleared some of the vegetation and improved the public areas by improving security and providing facilities for a range of activities (Emms 2006).

The people interviewed had not previously visited the site and were brought there by bus. The discussions took place while walking along a route designed by the researcher so that it would not exhaust the interviewees.

As this landscape was a former industrial site, it was not viewed initially by the interviewees as attractive. More specifically, they found the paths inappropriate for easy walking and in terms of naturalness, some found it very natural, but its negative effect on visibility increased their feeling of fear. The poor visibility increased the element of surprise, but made it difficult to conceive it as a landscape. This attribute was also connected with the mysteriousness of this landscape. They believed that the lack of management resulted in the vast amount of vegetation in this park. Others had a more positive view in that the naturalness increased their feeling of tranquillity. Almost half found it had a positive and relaxing effect while the other half found it increased their sense of fear and insecurity (Fig. 4).

Although this area is located near bus stations, the interviewees did not find it easily accessible, perhaps due to its emptiness. Smoothness was not an attribute of this area, which hindered its exploration. High ecological value associated with the river created a sense of identity and the sound of birds, the river and leaves resulted in a unique and enjoyable experience. Complexity was noted by some interviewees, which they attributed to the dense vegetation. Some of them related the poor visibility to a lack of variety but others did not know what constituted the landscape, as there was a lack of natural features, like the river. However, most of them viewed the landscape as boring, because of a lack of variety. Safety issues affected many other attributes or were associated with them. Lack of safety was viewed as the most important impediment to regularly visiting 


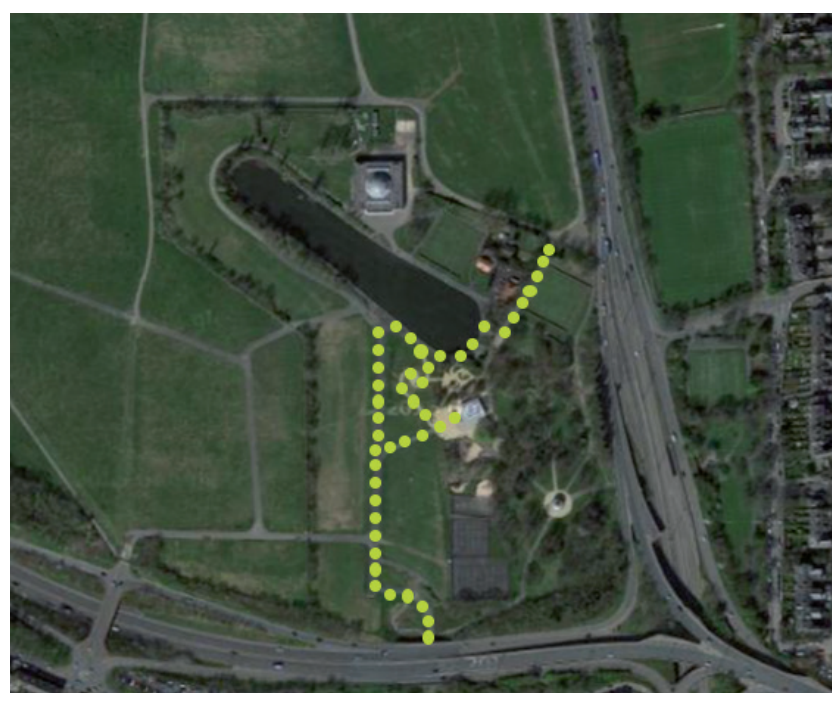

Fig. 6 Route in Exhibition Park along which people were interviewed (Source: Google maps).

and exploring this landscape, especially if alone. Thus, although some attributes of this landscape were viewed positively, safety is a major issue for people visiting this area (Fig. 5).

\section{Exhibition Park, Newcastle upon Tyne}

Exhibition Park is located in the centre of Newcastle and has existed since 1870 and was known previously as Bull Park. After 1885 North of England, Mining and Mechanical Engineering exhibitions were held in this space, which resulted in it being called Exhibition Park (Ainsley and Archnold 2013). It is one of the biggest parks in Newcastle upon Tyne with a variety of facilities including a coffee shop, basketball court, tennis court, skate-park, and a lake. This park, unlike Riverside Park is not covered with dense vegetation, but with cut grass and well laid out green spaces. It is now undergoing redevelopment funded by the Heritage Lottery and some parts are closed to the public. Fig. 6 shows the route of interview at Exhibition Park.

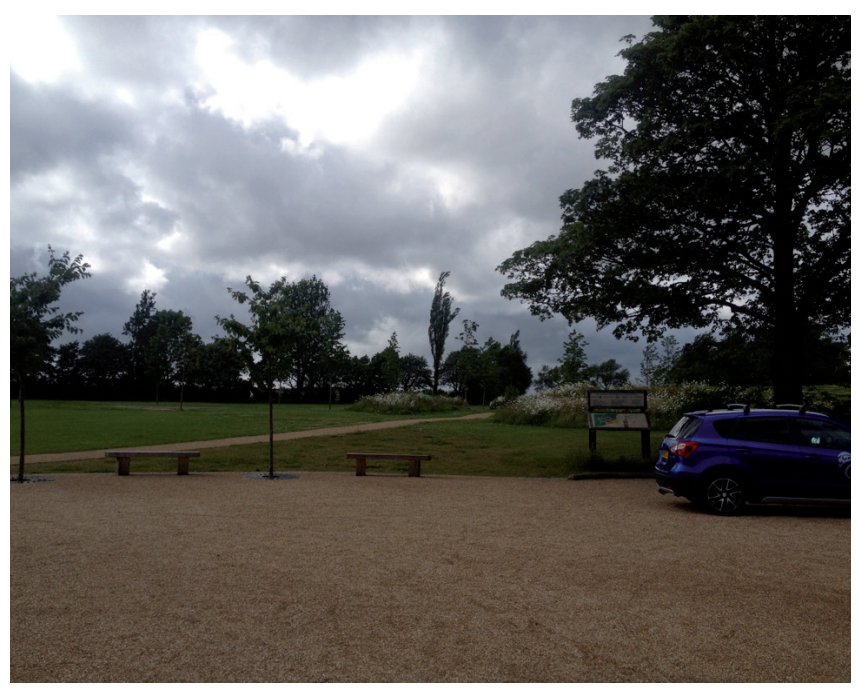

Fig. 7 Panoramic views of Exhibition park (Source: author).
The attributes listed in the previous section were discussed while walking in this landscape. This site was visited after returning from Riverside Park. Of the 7 interviewees, 3 had previously visited and were familiar with this park. The attributes were physical characteristics, image, identity, location and management.

Unlike their responses to Riverside Park, almost all of the interviewees responded in the same way to the attributes of this landscape. They regarded the high quality paths as suitable for all types of activities and abundant enough to provide quick access to different parts of this park. Hence, "smoothness" and "locomotion" were valued as important attributes of this park. In terms of "naturalness", they viewed wasteland as having a higher ecological value, but that naturalness and amount of vegetation in this park are sufficient. The large areas of grass were appreciated by some interviewees in that they provided suitable space for resting and chatting. Lack of dense vegetation was admired by the interviewees as it increased the "legibility" and "openness" of this site. They also related naturalness and the amount of vegetation to the "mysteriousness" of this site in terms of a lack of "surprise". "Complexity" of this space was considered to be low and "variety" was based on man-made and natural elements and the range of activities it offers. They believed this Park was sufficiently "tranquil", whereas Riverside Park was too complex and boring (Fig. 7).

"Rarity" and "sense of place" were the attributes most valued at this site and are associated with the existence of birds and swans near the lake. In terms of "location and accessibility", this site was considered to be very accessible and well located. They even compared it with the previous site and argued that psychologically, they consider this area to be more accessible even though both are located at similar distances from the centre and in similar situations. "Management" and "safety" of the park were ranked very highly and even related to each other as good management results in good safety. Summary of results are represented in following chart (Fig. 8).

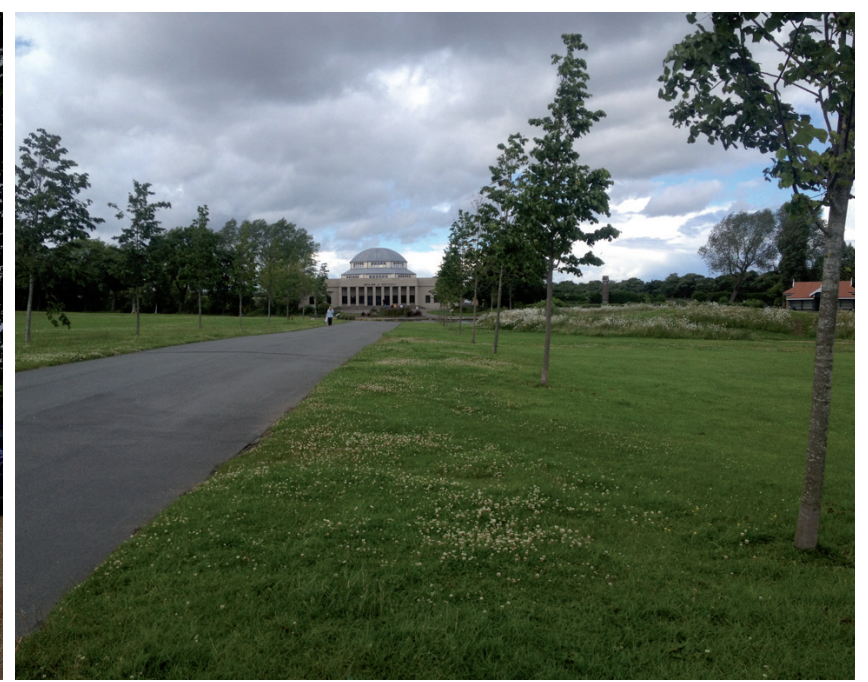




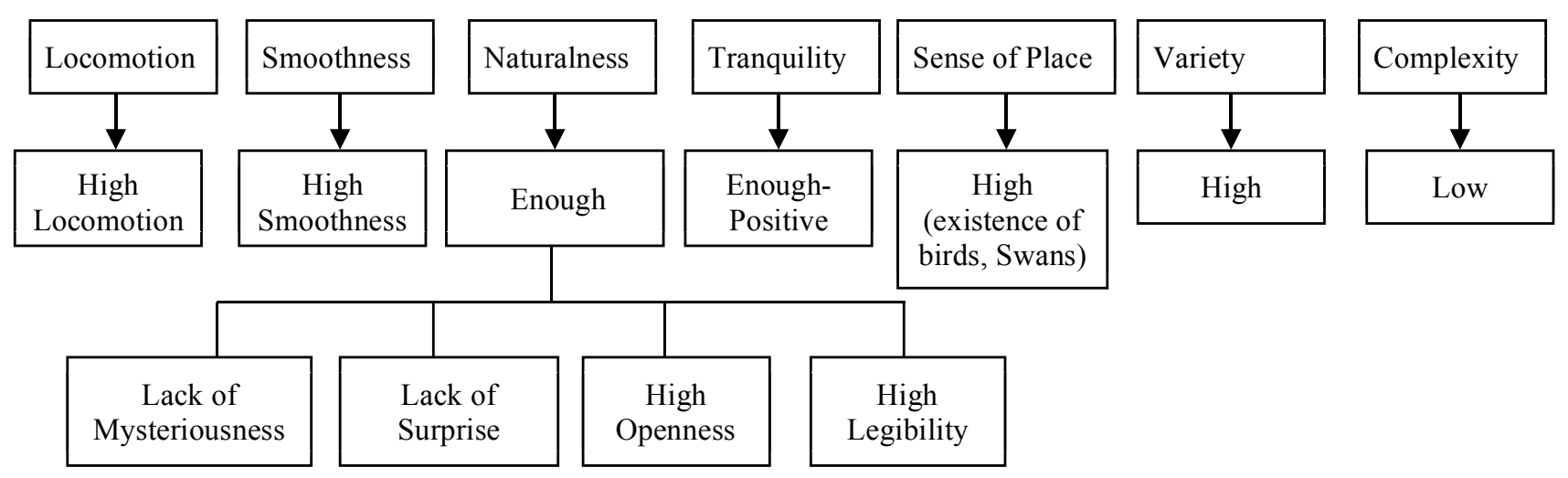

Fig. 8 Summary of the results for Exhibition Park.

\section{Discussion}

The subjective assessment of landscape quality is dependent upon people's status (Rogge et al. 2007), which influences their preferences. Attributes of landscape quality are those features of a landscape that are important in determining people's preferences. Attributes regarded as important were obtained from the literature published since 1970 by Kaplan (1979), Zube (1987) and Coeterier (1996), and categorized into four groups: physical characteristics that include naturalness, locomotion and smoothness, image and identity that includes surprise, variety, sense of place, tranquillity, rarity, legibility, mystery and openness, and location that includes accessibility and management especially maintenance and cleanness. Below is a table, in which the quality of the important attributes of the two landscapes studied are compared.

Table 1 Comparison of the quality of the attributes of Exhibition Park and Riverside Park.

\begin{tabular}{|l|c|c|}
\hline Landscape attributes & Riverside Park & Exhibition Park \\
\hline Locomotion & Low & High \\
\hline Smoothness & Low & High \\
\hline Naturalness & High & Medium \\
\hline Tranquillity & High & Medium \\
\hline Sense of Place & High & High \\
\hline Variety & Low & High \\
\hline Complexity & High & Low \\
\hline Mysteriousness & High & Low \\
\hline Surprise & High & Low \\
\hline Openness & Low & High \\
\hline Legibility & Low & High \\
\hline Management & Low & High \\
\hline Rarity & High & Low \\
\hline Safety & Low & High \\
\hline Accessibility & Low & High \\
\hline
\end{tabular}

The interviewees' responses to these attributes were similar to that reported in the literature reviewed. They valued some attributes similarly to that reported in the literature as positive, such as sense of place, management, openness, variety, smoothness, locomotion, surprise and safety. Complexity, which is valued negatively in the literature, was also considered to have a negative effect in terms of the coherence and legibility of an area. Other attributes were challenged and some were valued differently. Naturalness is an attribute that despite what some studies report, is not viewed positively. Nevertheless, naturalness is viewed in the same way as by Appleton (1975) in that it largely depends on the cultural background of the people, with some preferring to be in natural environments while others do not. However, all of the interviewees in this study preferred Exhibition Park, which is in a less natural setting. Very tranquil sites are viewed negatively. Accessibility is a controversial attribute as it is viewed differently in this research as the interviewees considered more the situation rather than the accessibility of the site. They believed that empty landscapes, although highly accessible, are not as accessible as crowded space. Mysteriousness is another attribute challenged by this study and unlike in the literature it was not viewed positively in terms of attracting more people to explore a site (Kaplan 1979). The interviewees viewed Riverside Park as mysterious, however, were not eager to visit this site again. This is also true for the feeling of surprise as although Riverside Park was viewed as surprising they were nevertheless not eager to explore it. The quality of these attributes is affected by level of safety and variety at the sites. This study revealed that the attributes are not equally important for qualifying landscapes as the interviewees considered some features as more influential than others in determining their preferences. Riverside Park was valued for its sense of identity, rarity, mystery, tranquillity and complexity; however, almost all of the interviewees were not willing to visit the site again. The major problem was the lack of safety as those who appreciated the tranquillity and mysteriousness of the area, were not eager to walk there alone. The sense of fear is a major attribute affecting the view of the overall quality of a particular site. After safety, lack of variety, management, legibility and locomotion are considered the most important. In Exhibition Park the interviewees talked positively about their feelings for the area mainly 


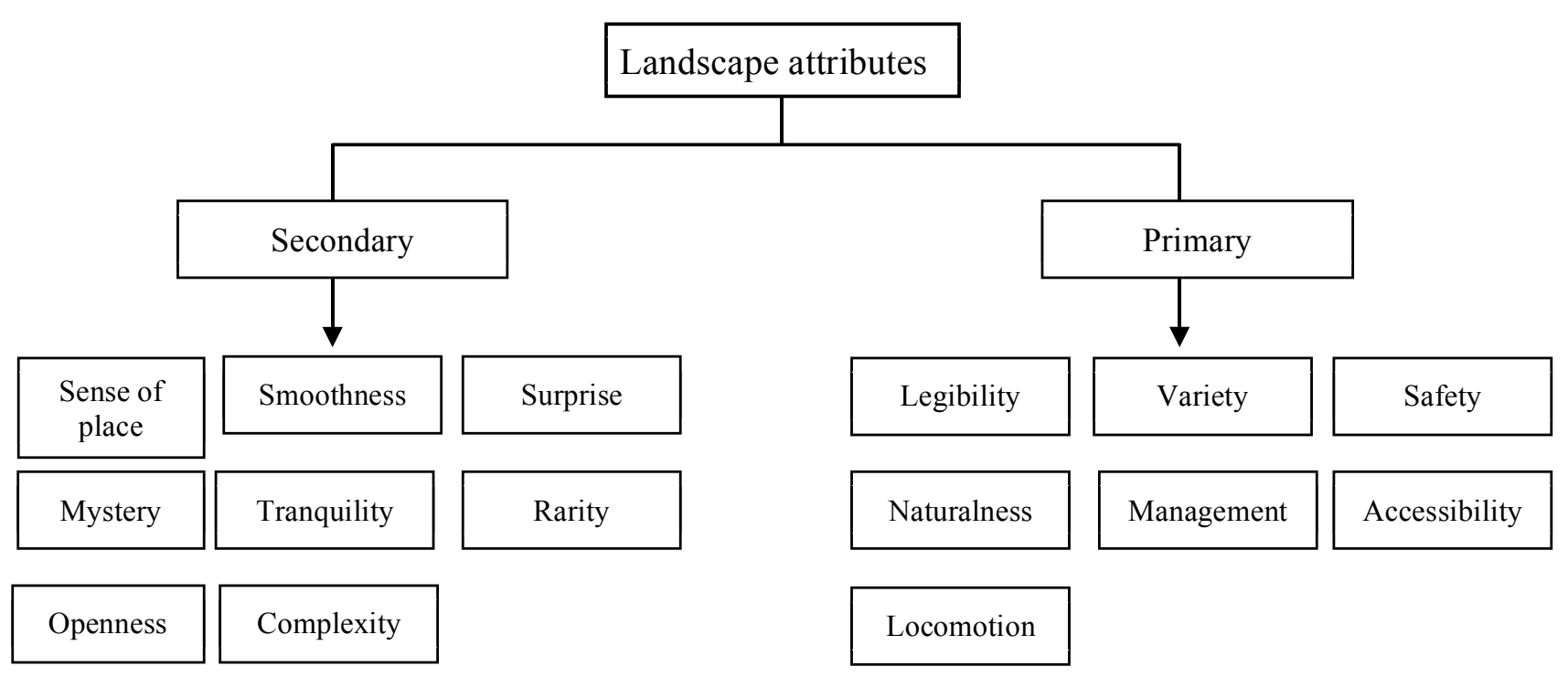

Fig. 9 Categories in which the various attributes of landscapes were classified.

in terms of variety, legibility, accessibility, management, locomotion and safety.

Although this site lacks surprise, mysteriousness, complexity and rarity the interviewees were interested in visiting the site again. People tend to choose and value landscapes that provide them with the possibility of experiencing a wide range of activities. Accessibility, management and legibility are also significant attributes determining the quality of a landscape. Overall, although Riverside Park was valued for its tranquillity, sense of identity, sense of place, rarity and mystery, it was not viewed as a high-quality landscape as poor safety was a major issue and locomotion, management and lack of variety were also influential. Although Exhibition Park lacked rarity, mystery, and to some extent a sense of place, it was valued very highly by all the interviewees, with some attributes being more influential in determining the quality of this site.

This research considers the difference between the attributes of landscapes and categories them as either primary or secondary. Based on the views of the interviewees the primary attributes are locomotion, safety, variety, legibility, management, accessibility and naturalness, and secondary attributes smoothness, surprise, sense of place, complexity, tranquillity, rarity and mystery.

\section{Conclusions}

Landscapes provoke unique feelings, meanings and concepts that can effect senses of identity (Pouya and Behbahani 2017), physical and psychological health (Abraham et al. 2010) and satisfaction of the environment (Kearney 2006). Understanding the quality of these landscapes in terms of people's perception can help planners to define the values of environments and result in better decisions. In order to achieve this one needs to be more rigorous in defining landscape quality and the ways, in which perceptual quality is assessed. Using the methods of assessing landscape quality cited in the literature published over the last five years, a framework for assessing the quality of landscapes was developed. Although several recent studies on landscape quality were carried out using photographs (Keshtkaran et al. 2017; Gungor and Polat 2018; Roth et al. 2018), in this study people were brought to the landscapes and questioned about their feelings an analysis of which revealed that certain attributes, like safety, can have a marked effect on their assessment of the quality of the landscape. Visiting a landscape is more likely to give them an accurate picture of safety than looking at photographs. Some attributes, such as safety and accessibility, are more important for people when assessing the quality of a landscape and visiting the landscape gives them a better idea of the quality of these attributes. This systematic study of the assessment of landscape quality is based on people's views when actually visiting urban green landscapes. The results of this study will help with the planning and management of landscapes. Highlighting those attributes that are of primary importance (legibility, variety, safety, naturalness, management, accessibility and locomotion) should help policymakers and planners to quickly evaluate landscapes as it greatly reduces the number of attributes that need to be evaluated. This is in addition to existing park evaluator tools, such as The Trust for Public Land Park Score. It will place more emphasis on the quality of urban green spaces, rather than the existence of a park or green space.

\section{REFERENCES}

Abraham A, Sommerhalder K, Abel T (2010) Landscape and well-being: a scoping study on the health-promoting impact of outdoor environments. Int J Public Health 55: 59-69.

Ahern K, Cole L, Land Use Consultants (2009) European Landscape Convention Guidance Part 2: Integrating the Intent of the ELC into Plans, Policies and Strategies, Natural England. 
Ainsley T, Archbold E (2013) Newcastle’s Parks, Special Collections, Newcastle University Library. http://www.ncl.ac.uk/library /specialcollections/exhibitions/current-and-past-exhibitions /so/parks.php.

Anderson E (1978) Visual resource assessment: Local perceptions of familiar natural environments. PhD thesis, University of Michigan, USA.

Appleton J (1975) The Experience of Landscape. John Wiley and Sons Ltd, London.

Barreira AP, Nunes LC, Guimarães MH, Panagopoulos T (2019) Satisfied but thinking about leaving: the reasons behind residential satisfaction and residential attractiveness in shrinking Portuguese cities. Int J Urban Sci. doi: 10.1080/12265934.2018.1447390.

Bell S (2014) Elements of visual design in the landscape. Routledge. London.

Bryman A (2001) Social Research Methods. Oxford University Press, Oxford.

Burton M, Rymsa-Fitschen C (2008) The 'landscape quality effect'. Creating a Setting for Investment. Project Report 9-25.

Coeterier JF (1996) Dominant Attributes in the Perception and Evaluation of the Dutch Landscape. Landscape Urban Plan 34: $27-44$.

Cosgrove D, Daniels S (1988) The Iconography of Landscape. Cambridge University Press, Cambridge.

Crowe S, Cresswell K, Robertson A, Huby G, Avery A, Sheikh A (2011) The Case Study Approach. BMC Med Res Methodol 11: $100-109$.

Daniel TC (2001) Wither scenic beauty? Visual landscape quality assessment in the 21st century. Landscape Urban Plan 54: 267-281.

De Val GDLF, Atauri JA, de Luci JV (2006) Relationship between landscape visual attributes and spatial pattern indices: a test study in Mediterranean-climate landscapes. Landscape Urban Plan 77: 393-407.

Dicicco B, Crabtree B (2006) Making Sense of Qualitative Research: The Qualitative Research Interview. Med Educ 40: 314-321.

Emms H (2006) Walker Riverside Area Action Plan. Newcastle City Council http://publications.naturalengland.org.uk/publication 148001.

Evans J, Jones P (2011) The Walking Interview: Methodology, Mobility and Place. Appl Geog 31: 849-858.

Fairbrother N (1970) New lives, new landscapes, Architectural Press. London.

Fairclough G (2002) A Forward-looking Convention: European Landscapes for the 21st Century. Naturopa 98: 5-6.

Frumkin H, Bratman GN, Breslow SJ, Cochran B, Kahn Jr PH, Lawler JJ, Levin PS, Tandon PS, Varanasi U, Wolf KL, Wood SA (2017) Nature contact and human health: A research agenda. Environ Health Persp 125: 075001-0750018.

Gallagher T J (1977) Visual preference for alternative natural landscapes, PhD Thesis, University of Michigan, USA.

Gavrilidis AA, Ciocănea CM, Niţă, MR, Onose DA, Năstase II (2016) Urban landscape quality index-planning tool for evaluating urban landscapes and improving the quality of life. Procedia Environ Sci 32: 155-167.

Gungor S, Polat AT (2018) Relationship between visual quality and landscape characteristics in urban parks. J Environ Prot Ecol 19: 939-948.

Jones P, Bunce G, Evans J, Gibbs H, Hein JR (2008) Exploring space and place with walking interviews. J Res Pract 4: D2.

Kaplan R, Kaplan S, Ryan RL (1998) With People in Mind: Design and Management of Everyday Nature. Island Press, Washington.
Kaplan R, Kaplan S, Brown T (1989) Environmental Preference, A Comparison of Four Domains of Predictors. Environ Behav 21: 509-530.

Kaplan S (1979) Perception and landscape: conceptions and misconceptions. In: Elsner GH, Smardon RC (eds) Technical coordinators. Department of Agriculture 35: 241-248.

Kearney AR (2006) Residential development patterns and neighborhood satisfaction: Impacts of density and nearby nature. Environ Behav 38: 112-139.

Keshtkaran R, Habibi A, Sharif H (2017) Aesthetic Preferences for Visual Quality of Urban Landscape in Derak High-Rise Buildings (Shiraz). J Sustain Dev. doi: 10.5539/jsdv10n5p94.

Lothian A (1999) Landscape and the Philosophy of Aesthetics: Is Landscape Quality Inherent in the Landscape or in the Eye of the Beholder. Landscape Urban Plan 44: 177-198.

Macpherson H (2016) Walking Methods in Landscape Research: Moving Bodies, Spaces of Disclosure and Rapport. Landscape Res 41: 425-432.

Mah A (2010) Memory, Uncertainty and Industrial Ruination: Walker Riverside, Newcastle upon Tyne. Int J Urban Regional 34: 398-413.

Nassauer JI (1995) Messy Ecosystems, Orderly Frames. Landscape J 14: $161-170$.

Orueta FD (2007) Madrid: Urban regeneration projects and social mobilization. Cities 24: 183-193.

Parsons R, Tassinary LG, Ulrich RS, Hebl MR, Grossman-Alexander M (1998) The view from the road: Implications for stress recovery and immunization. J Environ Psychol 18: 113-140.

Pouya S, Behbahani HI (2017) Assessment of the visual landscape quality based on the subjectivist paradigm to design the memorial garden. Türkiye Ormancllık Dergisi 18: 171-177.

Rogge E, Nevens F, Gulinck H (2007) Perception of Rural Landscapes in Flanders: Looking Beyond Aesthetics. Landscape Urban Plan 82: 159-179.

Roth M, Hildebrandt S, Röhner S, Tilk C, Schwarz-von Raumer HG, Roser F, Borsdorff M (2018) Landscape as an area as perceived by people: Empirically-based nationwide modelling of scenic landscape quality in Germany. J Digit Landscape Architecture 3: 129-137.

Ruelle C, Halleux J, Teller J (2013) Landscape Quality and Brownfield Regeneration: A Community Investigation Approach Inspired by Landscape Preference Studies. Landscape Res 38: 75-99.

Selman P (2012) Sustainable Landscape Planning, The Reconnection Agenda, Routledge. London and New York.

Seymour V (2016) The human-nature relationship and its impact on health: A critical review. Front Public Health. doi: 10.3389 /fpubh.2016.00260.

Sharp J, Pollock V, Paddison R (2005) Just art for a just city: Public art and social inclusion in urban regeneration. Urban Stud 42: 1001-1023.

Starman AB (2013) The Case Study as a Type of Qualitative Research. J Contemp Educ Stud 64: 28-43.

Swanwick C (2002) Landscape Character Assessment: Guidance for England and Theory. Landscape Plan 9: 1-33.

Tempesta T (2014) People's preferences and landscape evaluation in Italy: a review. New Medit 13: 50-59.

The Research Box, Land Use Consultants, Minter R (2009) Experiencing Landscapes; Capturing the 'Cultural Services' and 'Experiential Qualities' of Landscape. Natural England NECR024.

Tveit M, Ode Å, Fry G (2006) Key concepts in a framework for analysing visual landscape character. Landscape Res 31: $229-255$. 
Wu Y, Bishop I, Hossain H, Sposito V (2006) Using GIS in Landscape Visual Quality Assessment. Applied GIS 2: 18.1-18.20.

Zube EH (1987) Perceived Land Use Patterns and Landscape Values. Landscape Ecol 1: 37-45.
Zube EH, Pitt DG, Anderson TW (1974) Perception and measurement of scenic resources in the Southern Connecticut River Valley. Landscape Res 1: 10-11. 